\title{
Comparative visual performance with monofocal and multifocal intraocular lenses
}

\author{
Kjell Gunnar Gundersen 1,* \\ Richard Potvin',* \\ 'Privatsykehuset Haugesund, \\ Haugesund, Norway; ${ }^{2}$ Science \\ in Vision, Burleson, TX, USA
}

*These authors contributed equally to this work
This article was published in the following Dove Press journal:

Clinical Ophthalmology

8 October 2013

Number of times this article has been viewed

Background: To compare near, intermediate, and distance vision, and quality of vision using appropriate subjective questionnaires, when monofocal or apodized diffractive multifocal intraocular lenses (IOLs) are binocularly implanted.

Methods: Patients with different binocular IOLs implanted were recruited after surgery and had their visual acuity tested, and quality of vision evaluated, at a single diagnostic visit between 3 and 8 months after second-eye surgery. Lenses tested included an aspheric monofocal and two apodized diffractive multifocal IOLs with slightly different design parameters. A total of 94 patients were evaluated.

Results: Subjects with the ReSTOR ${ }^{\circledR}+2.5$ D IOL had better near and intermediate vision than those subjects with a monofocal IOL. Intermediate vision was similar to, and near vision slightly lower than, that of subjects with a $\operatorname{ReSTOR}^{\circledR}+3.0 \mathrm{D}$ IOL implanted. The preferred reading distance was slightly farther out for the $+2.5 \mathrm{D}$ relative to the $+3.0 \mathrm{D}$ lens, and farthest for the monofocal. Visual acuity at the preferred reading distance was equal with the two multifocal IOLs and significantly worse with the monofocal IOL. Quality of vision measures were highest with the monofocal IOL and similar between the two multifocal IOLs.

Conclusion: The data indicate that the ReSTOR +2.5 D IOL provided good intermediate and functional near vision for patients who did not want to accept a higher potential for visual disturbances associated with the ReSTOR +3.0 D IOL, but wanted more near vision than a monofocal IOL generally provides. Quality of vision was not significantly different between the multifocal IOLs, but patient self-selection for each lens type may have been a factor.

Keywords: multifocal IOL, near vision, cataract, presbyopia

\section{Background}

Diffractive optics has been incorporated into multifocal intraocular lens (IOL) designs for decades; a more recent design is the apodized partial-optic diffractive lens, approved for use in the USA as the AcrySof ${ }^{\circledR} \operatorname{ReSTOR}^{\circledR}+4.0$ lens in March of 2005. ${ }^{1}$ This lens features a central diffractive zone and a peripheral refractive-only zone, such that with large pupils relatively less light is directed to the near focus. ${ }^{2}$ An additional model of this lens is the AcrySof IQ ${ }^{\circledR}$ ReSTOR +3.0 D lens, featuring the same light distribution pattern but a lower powered add, approximately $2.3 \mathrm{D}$ at the corneal plane, compared to $3 \mathrm{D}$ with the original +4 add. This lens provides better intermediate vision than the +4 model with no evident change in visual disturbances. The preferred reading distance for the +3 lens was near $40 \mathrm{~cm}$, whereas with the +4 add the preferred reading distance was about $32 \mathrm{~cm}^{3,4}$

Any IOL that splits light for the purposes of providing distinct near and distant images creates the potential for visual disturbances that may be higher than for a
Correspondence: Kjell Gunnar Gundersen

Privatsykehuset Haugesund, Haraldsgaten I39,

5527 Haugesund, Norway

Email kggunder@gmail.com 
monofocal IOL. The photic phenomena most often reported as higher are glare and halos, particularly halos. ${ }^{5,6}$ Specific design elements can alter the amount of light directed to near and distant foci, and apodization can be used to modify that light distribution with varying pupil size. Both diffractive design and degree of apodization can affect the potential for glare and halos in diffractive multifocal lens designs. ${ }^{7}$

In 2012 the AcrySof IQ ReSTOR +2.5 D lens received Conformité Européenne (CE) mark and became available in Europe, based on bench testing demonstrating the optical differences between it and previous models. ${ }^{8}$ There were two major modifications to the lens design. The first was a change in the distribution of light to distance and near foci with varying pupil size. Figure 1 illustrates this change - the ratio of distant to near light is higher in the new model, which was expected to reduce the potential for glare and halos associated with the out-of-focus near light when viewing at distance, as well as improving distance vision. The second modification was a lowering of the add power from $3.0 \mathrm{D}$ to $2.5 \mathrm{D}$, measured at the IOL plane. This was expected to change the add power at the corneal plane from approximately 2.3 $\mathrm{D}$ to about 1.9 D (using a nominal $5.55 \mathrm{~mm}$ effective anterior chamber depth (ACD) and $20 \mathrm{D}$ lens power), moving the patient's reading distance out from about $40 \mathrm{~cm}$ to about $50 \mathrm{~cm}$.

This study was designed to provide the first clinical data related to the visual performance of the new ReSTOR $+2.5 \mathrm{D}$ IOL. The desire was to evaluate the lens as it would be used in practice, so recruitment was planned for after patients had undergone successful cataract surgery. This introduced some bias into the results as subjects self-selected for each of the IOLs included, but because this is representative of clinical practice we considered the approach a positive feature of the study design.

\section{Methods}

This study was designed to evaluate visual function after bilateral implantation of a monofocal or diffractive apodized multifocal IOL. Only patients who had already had successful, uncomplicated cataract surgery with appropriate lenses binocularly implanted were eligible for inclusion. Three groups of patients were studied: those with bilateral AcrySof IQ monofocal lenses implanted, those with bilateral AcrySof IQ ReSTOR +3.0 D lenses implanted, and those with bilateral AcrySof IQ ReSTOR +2.5 D lenses implanted. Target enrollment was 32 patients in each group. Institutional review board approval was applied for and obtained before patients were enrolled (Southwest Independent Institutional Review Board, Inc., Fort Worth, TX, USA).

The study was conducted as a post-intervention diagnostic evaluation. A list of patients between 1 and 6 months postsurgery on their second eye was prepared. Patients without surgical complications were called and asked to return between 3 and 6 months postoperatively for one diagnostic test visit. The recruiting list was updated over time, and patients were randomly called until a particular group was fully enrolled. Some patients presenting for a routine postoperative follow up visit in the appropriate time window were invited to participate immediately following their routine visit. Patients signed an informed consent form outlining the nature of the study, acknowledging their agreement to participate and permitting use of their de-identified data for analysis.

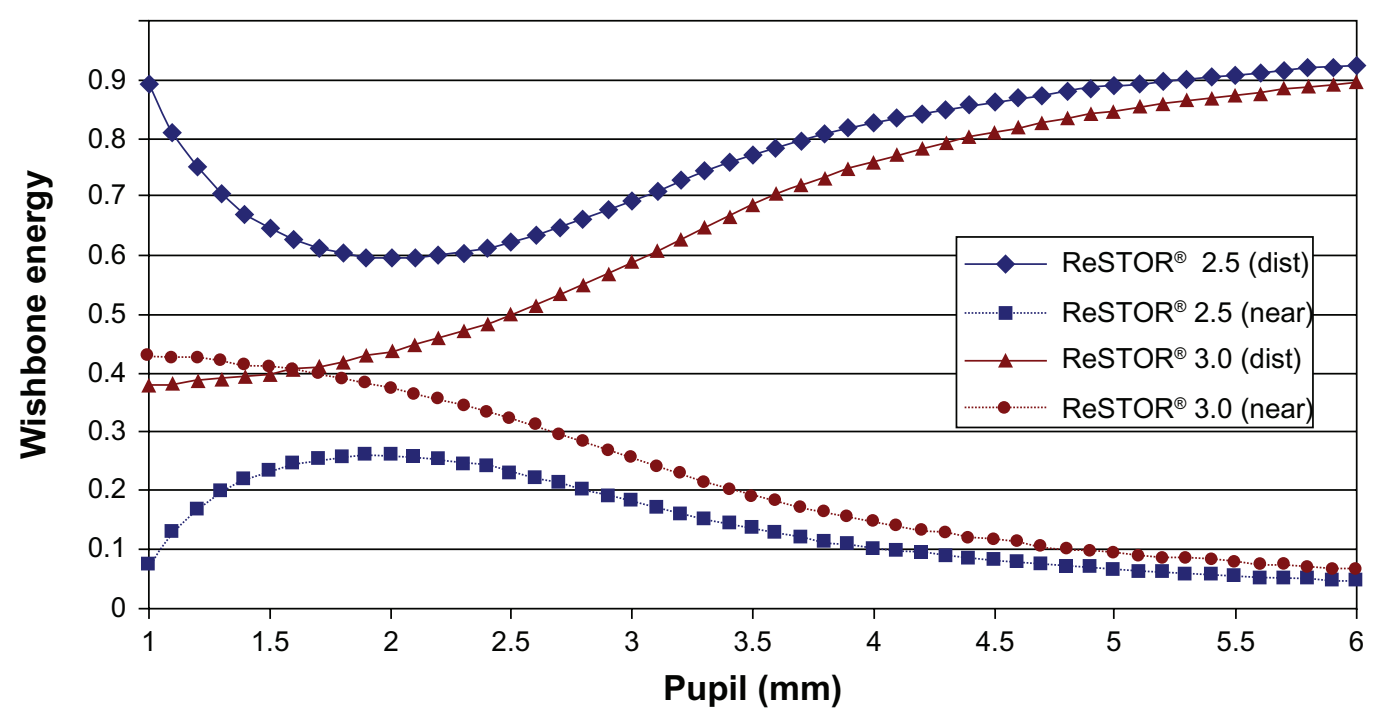

Figure I Comparative energy distribution of multifocal intraocular lenses. 
The single study visit involved the subjective evaluation of visual acuity (VA) and quality of vision. Basic demographic data were collected and enrollment qualification was established as described in the protocol. Briefly, subjects must have had uncomplicated bilateral surgery with one of the three IOLs under study and no ocular or systemic pathology that might have affected their best-corrected postoperative VA.

A manifest refraction was performed and VA was tested using standard high contrast log minimum angle of resolution (logMAR) Early Treatment Diabetic Retinopathy Study charts at $4 \mathrm{~m}, 60 \mathrm{~cm}$, and $40 \mathrm{~cm}$ under photopic conditions. VA was tested monocularly and binocularly, in the uncorrected and best distance-corrected states. The preferred distance for near work and the associated logMAR VA were also measured, with the patient choosing their preferred reading distance and reading the $60 \mathrm{~cm} \log M A R$ chart. The raw $\log$ MAR VA at this preferred reading distance was then corrected to provide the actual logMAR VA at that preferred reading distance. Low contrast (13\%) VA was tested at distance, with the best distance-correction in place. During the visit the subject was also asked to complete the Quality of Vision questionnaire, and the National Eye Institute (NEI) Visual Function Questionnaire near vision subset of questions. Both of these subjective instruments have been validated and can be scored using Rasch analysis. ${ }^{9}, 10$

Clinical data were tabulated and de-identified on case report forms, along with VA data from a computerized data collection system. Preliminary data checking and analysis was performed using Access database software (Microsoft Corporation, Redmond, WA, USA). The preliminary analysis included tabulating monocular and binocular data. Statistical analyses were performed using the Statistica data analysis software system, Version 10 (StatSoft, Inc., Tulsa, OK, USA).

For uncorrected and best-corrected VA, a two-way analysis of variance (ANOVA) was performed using test group and test distance as the categorical variables. Other measures were tested using ANOVA, analysis of covariance or, when categorical, the Kruskal-Wallis test. Significance was set at $P \leq 0.05$. Rasch analysis was applied to the questionnaire results.

The primary measure of interest was the difference in VA between groups at the various test distances when bestcorrected for distance. Other measures of interest were the differences in near visual function and subjective quality of vision as reported in the questionnaires, and the differences in the preferred reading distance and acuity at that distance.

\section{Results}

Planned enrollment was 96 patients, 32 in each group, with the diagnostic visit between 3 and 6 months. Actual enrollment was 94 patients, with one additional ReSTOR +3.0 D patient and three fewer monofocal (AcrySof IQ) patients. Scheduling changes resulted in several patients being examined in the seventh month, but all groups were affected and sensitivity testing of the various results versus the time since surgery (in days) revealed no significant effect from the slightly longer time interval.

A summary of the patient demographics is shown in Table 1; there were several differences in the groups. The average age of the monofocal patients was significantly higher than for the multifocal IOLs (ANOVA, $P<0.001$ ). This was largely due to the inclusion of refractive lens exchange patients (clear lensectomy and implantation of an IOL) who were limited to the multifocal groups; age was not different between the two multifocal groups (post-hoc Tukey's Honestly Significant Difference test, $P=0.96$ ). The percentage of males was higher in the ReSTOR $+2.5 \mathrm{D}$ group (Kruskal-Wallis test, $P<0.001$ ).

Table 2 summarizes the refractive outcomes for the three IOLs. There was slightly less refractive sphere in the ReSTOR +3.0 D group and slightly higher postoperative astigmatism in the AcrySof IQ group. While statistically significant, the measured differences were clinically nominal $(<0.25 \mathrm{D})$. The mean spherical equivalent refractive error was comparable between IOLs.

Figure 2 shows the binocular best distance-corrected VA by lens at the different standard test distances. The patterns were as expected from the lens designs, with the monofo-

Table I Study population characteristics

\begin{tabular}{|c|c|c|c|c|c|c|}
\hline Group & n (patients) & $\%$ male & Age & Cataract & RLE & $\begin{array}{l}\text { Time since } \\
\text { surgery (days) }\end{array}$ \\
\hline AcrySof IQ ${ }^{\circledR}$ monofocal & 29 & 41 & $74 \pm 8(6 I-87)^{*}$ & 29 & & $149 \pm 43(92-216)$ \\
\hline ReSTOR $^{\circledR}+2.5$ multifocal & 32 & $72 *$ & $59 \pm 9(42-74)$ & 14 & 18 & $128 \pm 45(85-215)$ \\
\hline ReSTOR $^{\circledR}+3.0$ multifocal & 33 & 36 & $58 \pm 10(4 \mid-79)$ & 14 & 19 & $158 \pm 44(89-219)$ \\
\hline
\end{tabular}

Note: *Significantly different than other two groups.

Abbreviation: RLE, refractive lens exchange. 
Table 2 Postoperative refractive error

\begin{tabular}{|c|c|c|c|c|c|c|c|c|c|c|c|c|c|}
\hline & \multirow[t]{2}{*}{$\mathbf{n}$} & \multicolumn{4}{|c|}{ Sphere } & \multicolumn{4}{|l|}{ Cyl } & \multicolumn{4}{|l|}{ MRSE } \\
\hline & & Mean & SD & Min & $\operatorname{Max}$ & Mean & SD & Min & $\operatorname{Max}$ & Mean & SD & Min & Max \\
\hline $\operatorname{ReSTOR}^{\circledR}+3$ & 66 & 0.30 & 0.34 & -0.25 & 1.00 & -0.38 & 0.27 & -1.25 & 0.00 & 0.11 & 0.33 & -0.63 & 0.88 \\
\hline AcrySof IQ ${ }^{\circledR}$ & 58 & 0.46 & 0.50 & -0.50 & $\mathrm{I} .75$ & -0.63 & 0.54 & -2.00 & 0.00 & 0.15 & 0.45 & -0.75 & 1.38 \\
\hline \multirow[t]{2}{*}{$\mathrm{ReSTOR}^{\circledR}+2.5$} & 64 & 0.47 & 0.34 & 0.00 & 1.50 & -0.44 & 0.37 & -1.50 & 0.00 & 0.25 & 0.30 & -0.38 & 1.38 \\
\hline & $P$ value & \multicolumn{4}{|c|}{$0.02-\operatorname{ReSTOR}+3$ lower } & \multicolumn{4}{|c|}{0.01 - IQ greater } & \multicolumn{4}{|l|}{0.08} \\
\hline
\end{tabular}

Abbreviations: Cyl, cylinder; Max, maximum; Min, minimum; MRSE, mean refractive spherical equivalent; SD, standard deviation.

cal IOL showing a monotonic decrease in VA with nearer test distance, and the ReSTOR +3.0 D providing very good near acuity and a slight reduction at intermediate distance $(60 \mathrm{~cm})$. The ReSTOR $+2.5 \mathrm{D}$ intermediate acuity was slightly better than the ReSTOR $+3.0 \mathrm{D}$, but the difference was not statistically significant $(P=0.24)$. Mean near acuity $(40 \mathrm{~cm})$ was about 1.5 lines lower than for the ReSTOR +3.0 $\mathrm{D}$, but more than three lines better than with the monofocal IOL; both of these differences were statistically significant $(P<0.01)$. All IOLs provided excellent distance VA.

Figure 3 shows the differences in the age-adjusted low contrast VA at $4 \mathrm{~m}$. There was no statistically significant difference between the lenses $(P=0.06)$ but the performance of the ReSTOR $+2.5 \mathrm{D}$ appeared to be closer to the monofocal IOL than the ReSTOR +3.0 D IOL.

Figures 4 and 5 summarize the results when the subjects, with best distance correction in place, were asked to read the chart at their preferred reading distance. Figure 4 shows that distance for each IOL while Figure 5 contains the associated mean VA. Because logMAR is an angular subtense, these acuities were calculated individually and averaged; the VA was corrected by using a log transformation of the measured acuity, the calibrated chart distance (here, the $60 \mathrm{~cm}$ chart was used), and the patient's preferred reading distance. VA at the preferred reading distance was similar for the two multifocal IOLs and significantly worse with the monofocal IOL $(P<0.01)$. Patients with the ReSTOR $+2.5 \mathrm{D}$ lens preferred a farther reading distance than those with the ReSTOR +3.0 D lens.

Subjective near vision reported by subjects using the NEI near vision subscale, was not statistically significantly different by IOL $(P>0.07)$; patients were reporting on their habitual near vision, which could include use of spectacles. There was a statistically significant difference in the Rasch scores for the Quality of Vision questionnaire for frequency, severity, and the degree to which the quality of vision was

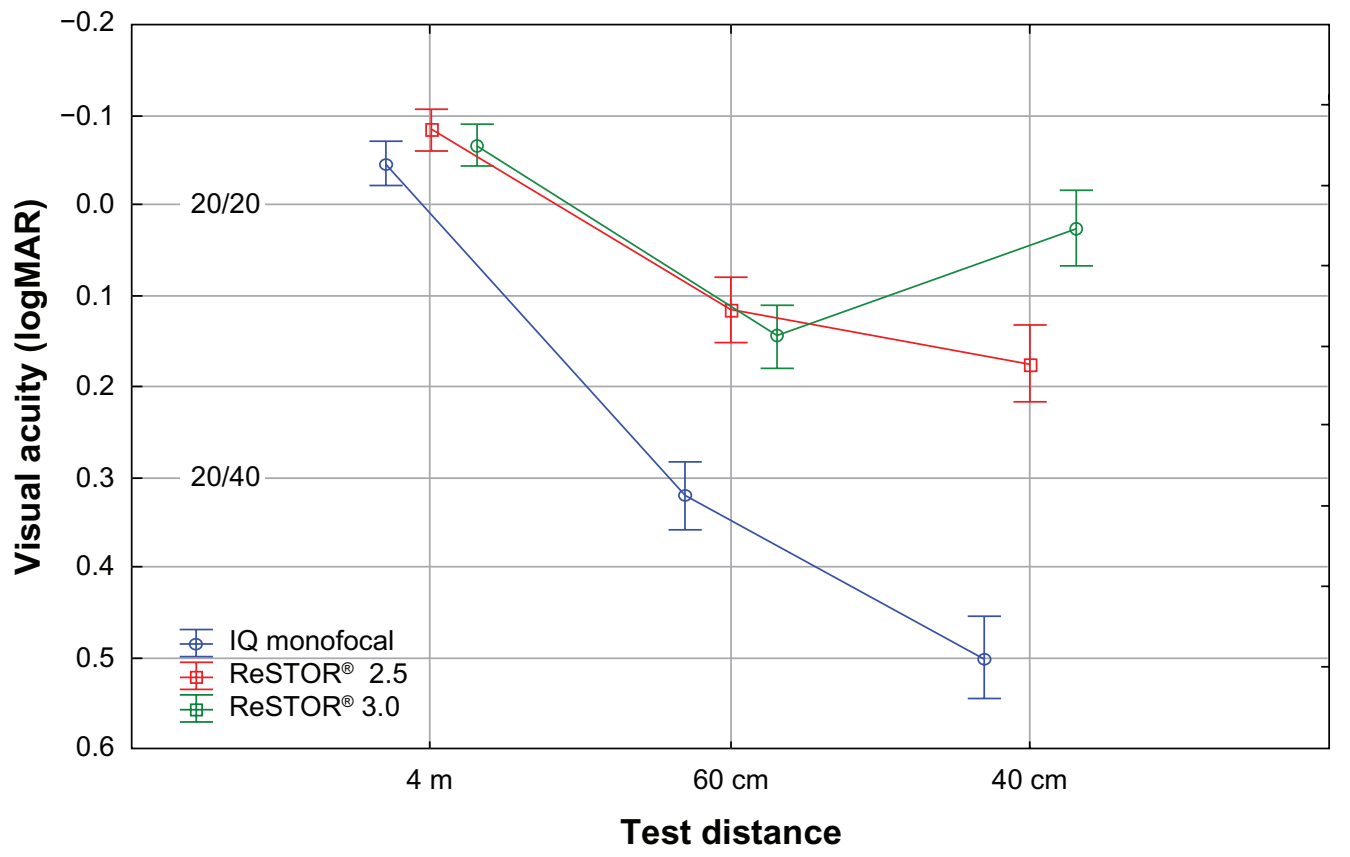

Figure 2 Best distance-corrected visual acuity by test distance and intraocular lens.

Note: Vertical bars denote 0.95 confidence intervals.

Abbreviation: $\log M A R$, minimum angle of resolution. 


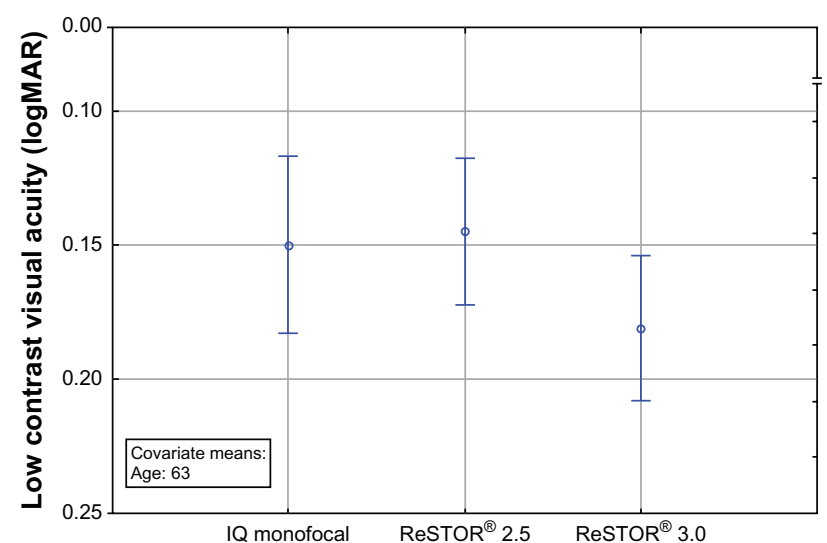

Figure 3 Age-adjusted distance low contrast (13\%) visual acuity. Note: Vertical bars denote 0.95 confidence intervals. Abbreviation: logMAR, minimum angle of resolution.

bothersome $(P<0.05)$. The two multifocal IOLs were not significantly different but the monofocal IOL had statistically significant lower (better) scores in all three measured categories. Figure 6 summarizes these findings. While not shown in this summary figure, the category of "halos" showed the greatest difference between the multifocal and monofocal IOLs ( $P<0.01$, for frequency, severity, and bothersome, Bonferroni corrected) but there was no statistically significant difference between the two ReSTOR lenses. As noted earlier, an analysis of covariance with time since surgery as a cofactor revealed no statistically significant time effect ( $P>0.6$ in all cases).

\section{Discussion}

This study provides the first clinical data related to the visual performance of the new ReSTOR $+2.5 \mathrm{D}$ apodized diffractive multifocal IOL, comparing it to the monofocal AcrySof IQ lens and the ReSTOR +3.0 D IOL. The latter has a higher

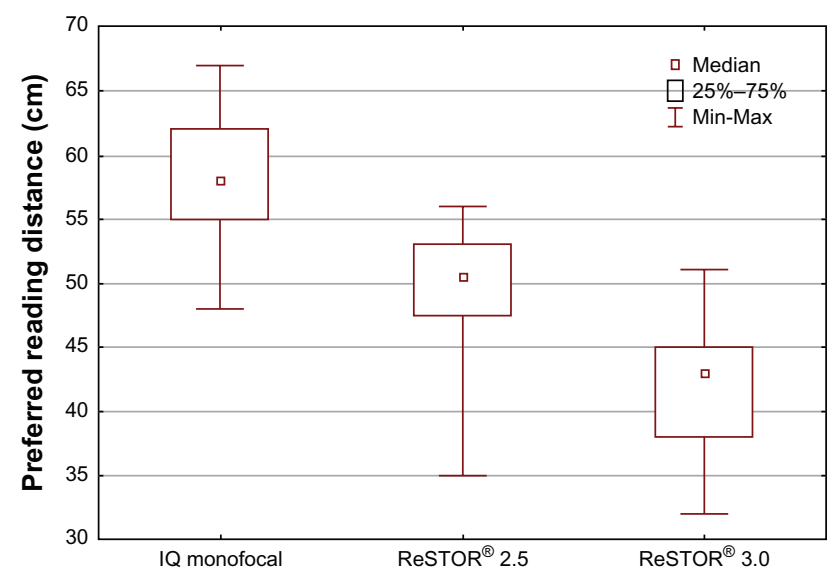

Figure 4 Preferred reading distance by implanted intraocular lens. Abbreviations: Max, maximum; Min, minimum.

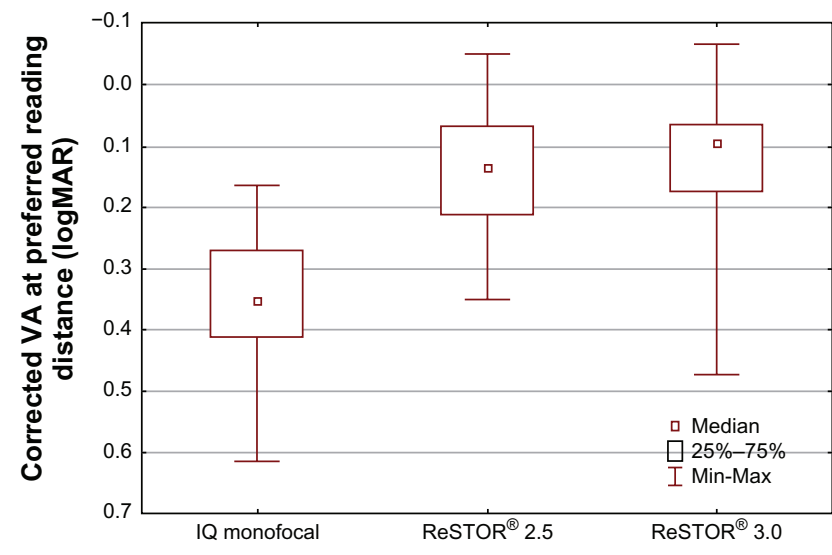

Figure $5 \mathrm{VA}$ at preferred reading distance by implanted intraocular lens. Note: $\log M A R 0=20 / 20$.

Abbreviations: logMAR, minimum angle of resolution; Max, maximum; Min, minimum; VA, visual acuity.

add than the ReSTOR $+2.5 \mathrm{D}$ and is designed to provide relatively more light for near vision. The AcrySof IQ and ReSTOR +3.0 D IOLs have been available in the European market for several years.

Postoperative VA data showed that the ReSTOR +2.5 D provided much better intermediate and near vision than a monofocal IOL, but the near vision was not as good as the ReSTOR +3.0 D lens. This was as expected. The results here also showed that intermediate vision was equivalent to that for the ReSTOR +3.0 D lens, offering patients who are more interested in arm's length activity (eg, computer work) an alternative to the higher add IOL. This was despite the lower amount of light being directed to the near focal point. The intent of the lens design was to provide "casual near vision;" the results suggest that this objective was met.

The preferred reading distance for subjects with the ReSTOR +2.5 D IOL implanted was about $50 \mathrm{~cm}$, slightly further out than the $40 \mathrm{~cm}$ distance of the ReSTOR +3.0 , consistent with the lens design. Near VA at the preferred reading distance was equivalent to the VA provided by the ReSTOR +3.0 D IOL and significantly better than that provided by the AcrySof IQ monofocal. Again, as a measure of usable near vision, the data indicate that the ReSTOR +2.5 D IOL is an effective improvement over a monofocal lens.

The tradeoff for the ReSTOR $+2.5 \mathrm{D}$ design relative to the ReSTOR +3.0 D design in terms of retaining more light for distance vision was expected to be better distance VA and lower levels of visual disturbance for the former lens. Distance VA for all three tested lenses was excellent, so no significant differences were observed. However, lower contrast VA provided some indication that the ReSTOR +2.5 D IOL design provided distance VA closer to 


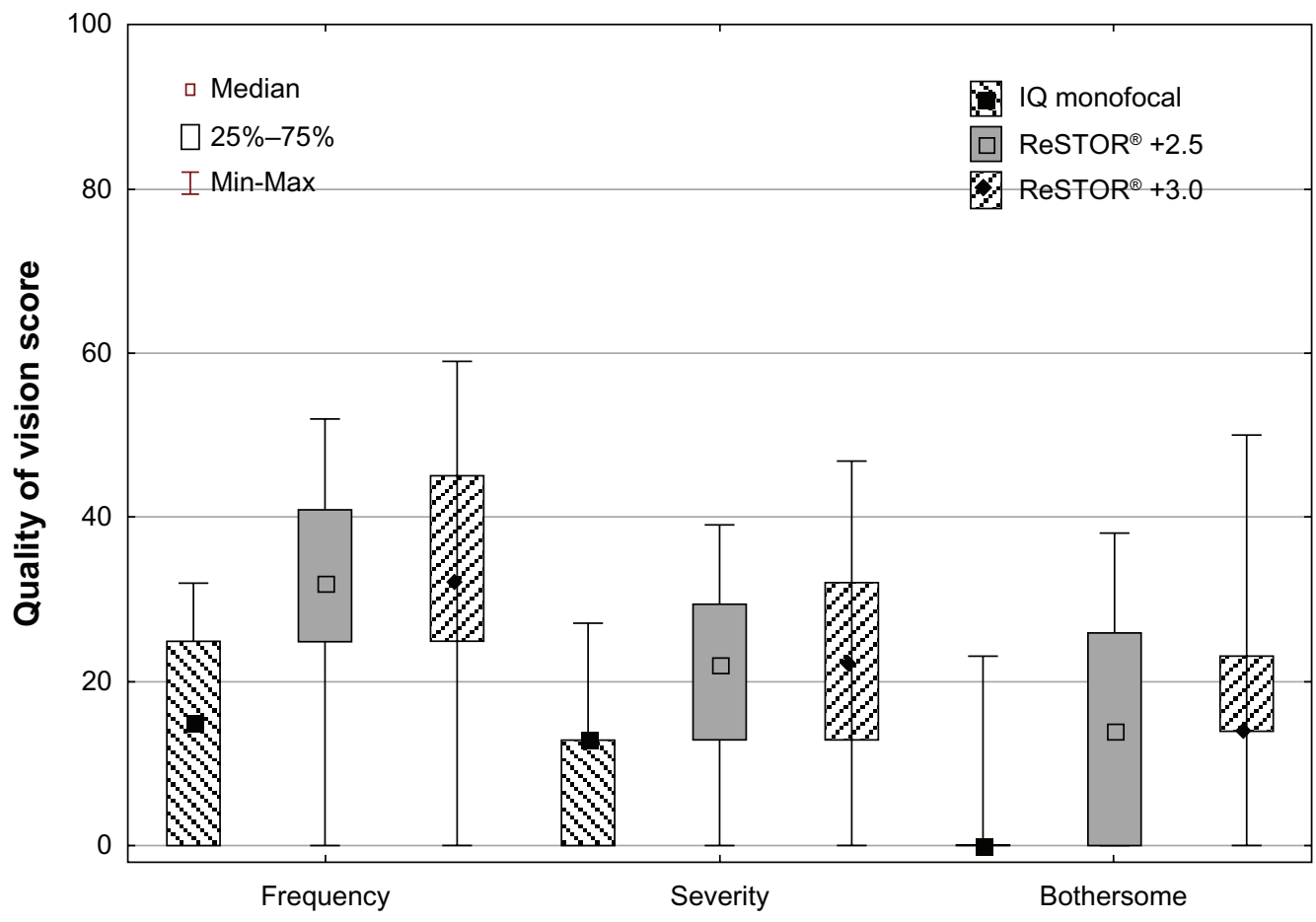

Figure 6 Box plots of quality of vision measures.

Abbreviations: Max, maximum; Min, minimum.

a monofocal lens than to the ReSTOR +3.0 D lens, though the results were not statistically significant. A recommendation for future studies would be to use a lower contrast chart (eg, $5 \%$ ) or contrast sensitivity testing to help better differentiate lens performance.

Initial expectation related to the subjective questionnaires was that the ReSTOR $+2.5 \mathrm{D}$ lens would have a visual quality profile between that of the monofocal IOL and the ReSTOR +3.0 D lens. This was not observed in this study. The NEI near vision questionnaire allows the use of reading glasses if they were used for the activities in question, to reflect actual patient behavior. As such, there was no statistically significant difference in near visual performance. Patients were not asked about whether they wore spectacles for each of these activities and this might be a useful addition to the questionnaire as administered here.

Differences in quality of vision measures were statistically significant, with the monofocal IOL being better relative to the multifocal IOLs; no statistically significant differences between the multifocal IOLs were observed. This may be a function of the study design, as noted in next paragraph. There may also be limits on the relative light distribution in largepupil situations that are not reflected in the pattern shown in Figure $1 .{ }^{11}$ The use of a validated Rasch-scale quality of vision score allows for comparison to other studies that have used the same scale. The monofocal data compare favorably to results for uncomplicated surgery reported by Skiadaresi et al. ${ }^{12}$

The study design involved postoperative recruitment of patients in each of the lens groups. Their selection of lens was not random, but was based on lifestyle decisions. With all multifocal IOLs, the general tradeoff is a higher likelihood of good near vision relative to a monofocal IOL, with a corresponding higher potential for some visual disturbances. Patients were advised of this before surgery. Those patients who chose the ReSTOR +2.5 D IOL were those who did not want to accept the higher potential for visual disturbances and higher likelihood of near good vision that is associated with the ReSTOR +3.0 D IOL. Their tolerance for glare and halos, then, would be expected to be lower than for patients who chose the ReSTOR +3.0 D lens. Their expectation would also be for a lower level of visual disturbances. The fact that their visual quality scores were not different than for patients with the ReSTOR +3.0 D IOL may be a reflection of this. It could merely imply that patient selection was appropriate; the level of visual disturbance relative to the expectation for visual disturbances appeared to be equal in the two groups. The only appropriate method to resolve this, and to establish a less biased quality of vision measure, would be a randomized prospective trial. 


\section{Conclusion}

The ReSTOR $+2.5 \mathrm{D}$ apodized diffractive IOL was designed as an alternative lens for patients who did not want to accept the higher potential for visual disturbances with the ReSTOR +3.0 D IOL, but who wanted more usable near vision than a monofocal IOL provided. The data from the current study suggest that the ReSTOR +2.5 D IOL provides such an alternative. Questions related to the relative quality of vision remain, but are likely to be answered only through a randomized prospective study design.

\section{Acknowledgments}

The authors acknowledge the assistance of Steffen Østenstad in collecting and tabulating the clinical data.

\section{Author contributions}

Richard Potvin (RP) and Kjell Gunnar Gundersen (KGG) designed the study. KGG provided the required clinical data. RP performed the statistical analyses. KGG and RP reviewed the results and wrote/reviewed the final paper.

\section{Disclosure}

KGG is a consultant to Alcon Laboratories, Inc. RP is a consultant to Alcon Laboratories, Inc. Alcon Laboratories, Inc. provided funding for this investigator-initiated study. Alcon Laboratories, Inc. was not involved in the study design or analysis of results. The decision to submit the manuscript for publication was made by Drs Gundersen and Potvin independent of Alcon Laboratories, Inc. input. The authors report no other conflicts of interest in this work.

\section{References}

1. Food and Drug Administration [webpage on the Internet]. Rockville MD, USA. Department of Health \& Human Services, letter to Alcon Research Ltd. Available from: http://www.accessdata.fda.gov/cdrh_docs/pdf4/ p040020a.pdf. Accessed September 23, 2013.

2. Davison JA, Simpson MJ. History and development of the apodized diffractive intraocular lens. J Cataract Refract Surg. 2006;32(5): 849-858.

3. Sun Y, Zheng D, Song T, Liu Y. Visual function after bilateral implantation of apodized diffractive multifocal IOL with a +3.0 or $+4.0 \mathrm{D}$ addition Ophthalmic Surg Lasers Imaging. 2011;42(4):302-307.

4. Santhiago MR, Wilson SE, Netto MV, et al. Modulation transfer function and optical quality after bilateral implantation of a +3.00 D versus a +4.00 D multifocal intraocular lens. $J$ Cataract Refract Surg. 2012;38(2):215-220.

5. Calladine D, Evans JR, Shah S, Leyland M. Multifocal versus monofocal intraocular lenses after cataract extraction. Cochrane Database Syst Rev. 2012;9:CD003169.

6. Cochener B, Lafuma A, Khoshnood B, Courouve L, Berdeaux G. Comparison of outcomes with multifocal intraocular lenses: a meta-analysis. Clin Ophthalmol. 2011;5:45-56.

7. Maxwell WA, Lane SS, Zhou F. Performance of presbyopia-correcting intraocular lenses in distance optical bench tests. $J$ Cataract Refract Surg. 2009;35(1):166-171.

8. Ophthalmology Times [webpage on the Internet]. Editor's Blog: The year of intraocular lenses (IOLs). Available from: http://ophthalmologytimes.modernmedicine.com/ophthalmologytimes/news/modernmedicine/modern-medicine-feature-articles/editors-blog-year-intraocula. Accessed September 23, 2013.

9. Pesudovs K, Gothwal VK, Wright T, Lamoureux EL. Remediating serious flaws in the National Eye Institute Visual Function Questionnaire. $J$ Cataract Refract Surg. 2010;36(5):718-732.

10. McAlinden C, Pesudovs K, Moore JE. The development of an instrument to measure quality of vision: the Quality of Vision (QoV) questionnaire Invest Ophthalmol Vis Sci. 2010;51(11):5537-5545.

11. Vega F, Alba-Bueno F, Millán MS. Energy distribution between distance and near images in apodized diffractive multifocal intraocular lenses. Invest Ophthalmol Vis Sci. 2011;52(8):5695-5701.

12. Skiadaresi E, McAlinden C, Pesudovs K, Polizzi S, Khadka J, Ravalico G. Subjective quality of vision before and after cataract surgery. Arch Ophthalmol. 2012;130(11):1377-1382.
Clinical Ophthalmology

\section{Publish your work in this journal}

Clinical Ophthalmology is an international, peer-reviewed journal covering all subspecialties within ophthalmology. Key topics include: Optometry; Visual science; Pharmacology and drug therapy in eye diseases; Basic Sciences; Primary and Secondary eye care; Patient Safety and Quality of Care Improvements. This journal is indexed on

\section{Dovepress}

PubMed Central and CAS, and is the official journal of The Society of Clinical Ophthalmology (SCO). The manuscript management system is completely online and includes a very quick and fair peer-review system, which is all easy to use. Visit http://www.dovepress.com/ testimonials.php to read real quotes from published authors. 